\title{
Extent of Microstructural Tissue Damage Correlates with Hemodynamic Failure in High-Grade Carotid Occlusive Disease: An MRI Study Using Quantitative T2 and DSC Perfusion
}

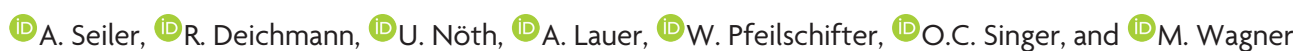
O- E E

\begin{abstract}
BACKGROUND AND PURPOSE: Chronic hemodynamic impairment in high-grade carotid occlusive disease is thought to cause microstructural abnormalities that might be subclinical or lead to subtle symptoms including cognitive impairment. Quantitative MR imaging allows assessing pathologic structural changes beyond macroscopically visible tissue damage. In this study, high-resolution quantitative $\mathrm{T} 2$ mapping combined with DSC-based PWI was used to investigate quantitative T2 changes as a potential marker of microstructural damage in relation to hemodynamic impairment in patients with unilateral high-grade carotid occlusive disease.
\end{abstract}

MATERIALS AND METHODS: Eighteen patients with unilateral high-grade ICA or MCA stenosis/occlusion were included in the study. T2 values and deconvolved perfusion parameters, including relative $C B F$, relative $C B V$, and the relative $C B F /$ relative $C B V$ ratio as a potential indicator of local cerebral perfusion pressure, were determined within areas with delayed TTP and compared with values from contralateral unaffected areas after segmentation of normal-appearing hypoperfused WM and cortical regions. Hemispheric asymmetry indices were calculated for all parameters.

RESULTS: Quantitative T2 was significantly prolonged $(P<.01)$ in hypoperfused tissue and correlated significantly $(P<.01)$ with TTP delay and relative $C B F /$ relative $C B V$ reduction in WM. Significant correlations $(P<.001)$ between TTP delay and the relative CBF/relative CBV ratio were found both in WM and in cortical areas.

CONCLUSIONS: Quantitative T2 can be used as a marker of microstructural tissue damage even in normal-appearing GM and WM within a vascular territory affected by high-grade carotid occlusive disease. Furthermore, the extent of damage correlates with the degree of hemodynamic failure measured by DSC perfusion parameters.

ABBREVIATIONS: $\mathrm{Al}=$ asymmetry index; $\mathrm{CPP}=$ cerebral perfusion pressure; $\mathrm{q}=$ quantitative; $\mathrm{rCBF}=$ relative $\mathrm{CBF} ; \mathrm{rCBV}=$ relative $\mathrm{CBV}$

$I_{d}^{n}$ patients with ICA and MCA occlusive disease, chronic hemodynamic compromise is associated with an increased risk of ischemic stroke ${ }^{1-4}$ because it may lead to hemodynamic infarction and it presumably also predisposes the patient to embolic phenomena. ${ }^{5}$ Apart from focal neurologic symptoms due to acute

Received November 28, 2017; accepted after revision March 15, 2018. From the Department of Neurology (A.S., W.P., O.C.S.), Brain Imaging Center (R.D., U.N.), and Institute of Neuroradiology (A.L., M.W.), Goethe University Frankfurt, Frankfurt, Germany.

Ralf Deichmann and Ulrike Nöth were supported by the Brain Imaging Center Bundesministerium für Bildung und Forschung (Germany) DLR 01GO0203, Deutsche Forschungsgemeinschaft (Germany) ZA 233/1-1.

Please address correspondence to Alexander Seiler, MD, Department of Neurology, Goethe University Frankfurt, Schleusenweg 2-16, 60528 Frankfurt, Germany; e-mail: Alexander.Seiler@kgu.de

- Indicates open access to non-subscribers at www.ajnr.org

三 Indicates article with supplemental on-line table.

Indicates article with supplemental on-line photo.

http://dx.doi.org/10.3174/ajnr.A5666 ischemia, chronic hemodynamic impairment in unilateral highgrade ICA stenosis or occlusion may be associated with measurable global cognitive impairment, ${ }^{6,7}$ even in patients without visible ischemic lesions on conventional MR images ("silent"). Pathophysiologically, these clinical findings seem to be related to microstructural changes, including diffuse demyelination, the loss of axons, and gliosis. ${ }^{6,8-12}$

On conventional MR imaging, ipsilateral atrophy and signal increase on T2WI due to increased water content and gliotic changes have been described in severe chronic hypoperfusion. ${ }^{13}$ However, in many patients, no abnormalities are visible on conventional T2WI, though microstructural damage associated with stenosis-related chronic hypoperfusion might be reasonably assumed. Compared with conventional MR imaging, quantitative (q)MR imaging techniques are more sensitive to microstructural and metabolic tissue changes. ${ }^{14,15}$ In patients with diffuse chronic hypoxia (ischemic leukoaraiosis), quantitative MR imaging including $\mathrm{qT} 2$ revealed significant T2 prolongation in the normal-appearing WM, suggesting mi- 
crostructural damage. ${ }^{14}$ Therefore, $\mathrm{qT} 2$ might detect subtle changes, including microstructural damage in the territory of a chronically stenotic cerebral artery that is not visible on conventional MR imaging, and might be a promising imaging biomarker for microstructural changes related to chronic hypoperfusion.

Because these microstructural changes possibly depend on the degree of hemodynamic failure and cerebral perfusion pressure (CPP) impairment, ${ }^{8}$ it might be interesting to investigate the correlation between potential qT2 changes in the dependent territory and hemodynamic measures, including the CPP. By means of $\mathrm{PET}$, the $\mathrm{CBF} / \mathrm{CBV}$ ratio has been validated as an indicator of local CPP, ${ }^{16}$ and a negative correlation with DSC-based TTP delay has been demonstrated in patients with unilateral ICA or MCA stenosis/occlusion. ${ }^{17}$ Consequently, if this relationship can be reproduced, DSC-based relative ( $\mathrm{r}$ ) $\mathrm{CBF} / \mathrm{rCBV}$ might be a suitable index for local CPP as well.

In this study, an advanced high-resolution qMRI technique combined with DSC perfusion imaging was used to explore qT2 changes in hypoperfused tissue in patients with high-grade ICA and MCA occlusive disease. The purpose was to evaluate the following: 1) whether qT2 mapping displays a significant increase of T2 values in chronically hypoperfused noninfarcted and normalappearing tissue as a sign of microstructural damage, and 2) whether these changes of qT2 are related to measures of hemodynamic impairment, including autoregulatory capacity and CPP.

\section{MATERIALS AND METHODS \\ Patients}

Eighteen consecutive patients, some having been described previously, ${ }^{18}$ with unilateral symptomatic or asymptomatic high-grade stenosis or occlusion of the ICA or MCA were included. Inclusion criteria were the following: 1) Doppler sonography evidence of unilateral, $>70 \%$ (NASCET criteria) high-grade extracranial ICA stenosis or ICA occlusion; or 2) Doppler sonography or MR angiographic evidence of a high-grade $(>50 \%)$ unilateral intracranial ICA or proximal MCA stenosis/occlusion. Patients with relevant bilateral stenoses (contralateral stenosis of $>50 \%$ ) were not considered for inclusion in the study. The study was approved by the local institutional review board, and written informed consent was obtained from all patients before study enrollment.

\section{MR Imaging Protocol}

MR imaging measurements were performed on a 3T whole-body scanner (Magnetom Trio; Siemens, Erlangen, Germany) using the body coil of the scanner for radiofrequency transmission and an 8-channel phased array head coil for signal reception. The MR imaging examination included quantitative T2 mapping as well as DWI and PWI, MRA, and conventional T1WI and T2WI.

Anatomic imaging was based on a T1-weighted MPRAGE sequence with the following imaging parameters: TR/TE/TI = $2250 / 2.6 / 900 \mathrm{~ms}, \mathrm{FOV}=256 \times 224 \times 144 \mathrm{~mm}^{3}$, whole-brain coverage, isotropic spatial resolution $=1 \mathrm{~mm}, 22 \%$ oversampling in the slice-encoding (left-right) direction to avoid aliasing, bandwidth $=200 \mathrm{~Hz} /$ pixel, excitation angle $=9^{\circ}$, duration $=7 \mathrm{~min}$ utes 23 seconds. This dataset was used for tissue segmentation.

Quantitative T2 mapping was based on a fast spin-echo sequence with an echo-train length of 11 echoes per excitation, an echo spacing of $17.1 \mathrm{~ms}$, and the following imaging parameters: 50 axial slices with 2-mm slice thickness, no interslice gap, $\mathrm{TR}=10$ seconds, bandwidth $=100 \mathrm{~Hz} /$ pixel, $180^{\circ}$ refocusing pulses, matrix size $=192 \times 132$ (readout $\times$ phase encoding), $\mathrm{FOV}=240 \times$ $165 \mathrm{~mm}^{2}$, and in-plane resolution $=1.25 \times 1.25 \mathrm{~mm}^{2}$. For quantitative T2-mapping, 5 datasets were acquired with different TE values $(17,86,103,120,188 \mathrm{~ms})$, keeping all other acquisition parameters constant. The total duration was 11 minutes 50 seconds.

PWI was based on a gradient-echo EPI sequence with the following imaging parameters: $\mathrm{TE}=35 \mathrm{~ms}$, TR $=1500 \mathrm{~ms}$, flip angle $=90^{\circ}, \mathrm{FOV}=192 \times 192 \mathrm{~mm}$, matrix $=64 \times 64$, slice thickness $=4 \mathrm{~mm}$, number of slices $=16$, voxel size $=2.0 \times 2.0 \times$ $4.0 \mathrm{~mm}^{3}$, and acquisition time $=1$ minute 15 seconds. The contrast agent $(0.1 \mathrm{mmol} / \mathrm{kg}$ of Gd-DTPA, Magnevist; Bayer HealthCare Pharmaceuticals, Wayne, New Jersey) was injected into an antecubital vein using a power injector at a rate of $5 \mathrm{~mL} / \mathrm{s}$ followed by a flush with $10 \mathrm{~mL}$ of saline.

\section{Image Postprocessing and Analysis}

Perfusion-weighted MR raw images were processed on a pixel-bypixel basis to generate maps of the nondeconvolved TTP, rCBF, and $\mathrm{rCBV}$. To determine the shape of the arterial input function, 2 experienced neuroradiologic readers manually selected 5-10 pixels in consensus over the proximal MCA in the unaffected hemisphere. For calculation of $\mathrm{rCBF}$ and $\mathrm{rCBV}$ maps, we used the model-independent (nonparametric) singular-value decomposition method described by Ostergaard et al. ${ }^{19}$

Further image postprocessing and analysis were performed with FMRIB Software Library tools (FSL, Version 5.0; https:// fsl.fmrib.ox.ac.uk/fsl). All images were skull-stripped before coregistration. Quantitative T2 maps were linearly coregistered to the T1-weighted images. Because PWI parameter maps do not provide sufficient anatomic contrast for coregistration, we used the following: The first volume of the PWI time-series, which showed adequate anatomic contrast for coregistration, was extracted and coregistered to the T1-weighted image, saving the coregistration matrix. This matrix was applied to coregister TTP, rCBF, and rCBV parameter maps to the T1-weighted image. For coregistration of DWI maps, the first diffusion-weighted image ( $b=0$, purely T2-weighted) was coregistered to the T1-weighted image. The coregistration matrix of this step was used for later coregistration of the diffusion-weighted image with $b=1000$ $\mathrm{s} / \mathrm{mm}^{2}$ to the $\mathrm{T} 1$-weighted image.

T1-weighted images were segmented with the FMRIB Automated Segmentation Tool (FAST; https://fsl.fmrib.ox.ac.uk/fsl/ fslwiki/FAST), ${ }^{20}$ yielding partial volume estimate maps for white matter, gray matter, and CSF. A lower partial volume estimate threshold of 0.95 was applied to both the WM and the GM maps. ${ }^{21}$ For segmentation of the cerebral cortex, voxels of noncortical structures, including subcortical lesions or (enlarged) perivascular spaces misclassified as GM, were removed from the GM maps. Both the WM and cortex maps were binarized to receive tissue masks for the qT2 and PWI parameter maps (Fig 1, upper row, and Fig 2A).

Maps of $\mathrm{rCBF}$ and $\mathrm{rCBV}$ were processed voxelwise to calculate maps of the $\mathrm{rCBF} / \mathrm{rCBV}$ ratio as possible indicators of local 


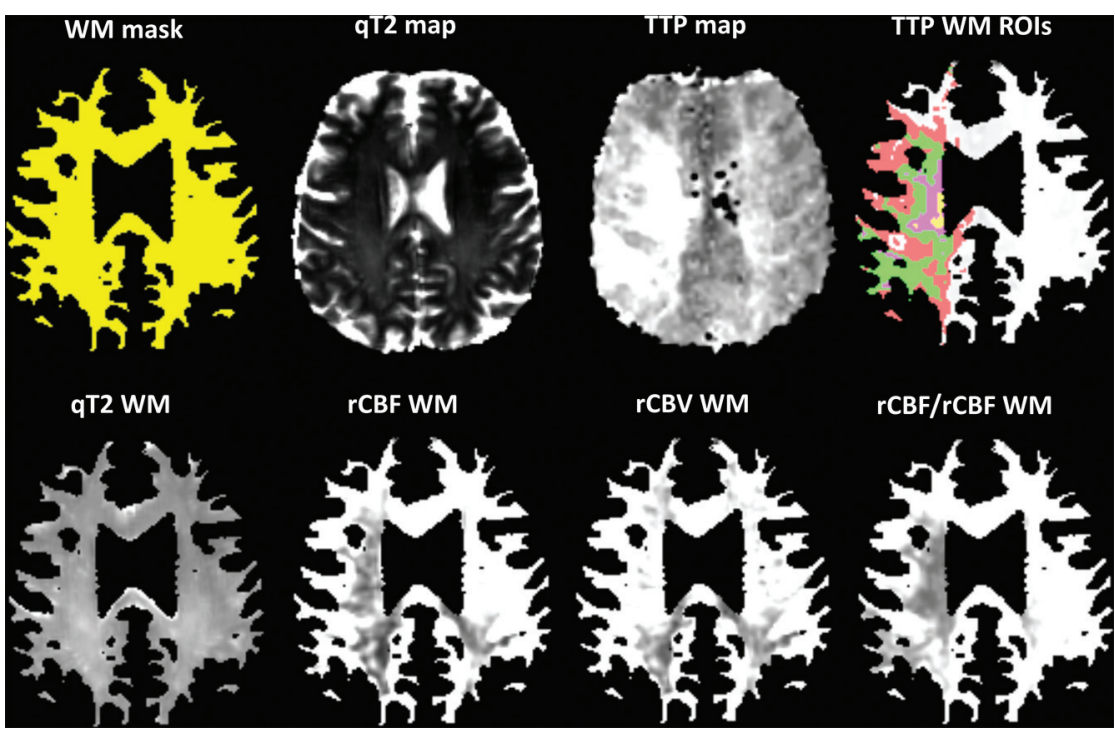

FIG 1. Illustration of image postprocessing and analysis in a patient with right-sided intracranial ICA stenosis. Upper row: WM mask obtained from segmentation of the Tl-weighted image, skull-stripped qT2, and TTP maps. ROls according to different TTP delay ranges for WM analysis are shown on the segmented image in the upper right corner: 0 - to 2-second delay (red), 2- to 4-second delay (green), 4- to 6-second delay (purple), and 6- to 8-second delay (yellow). Lower row: Segmented qT2 and perfusion parameter maps for WM analysis. Note the reduction of rCBF and the $\mathrm{rCBF} / \mathrm{rCBV}$ ratio in perfusion-delayed white matter.

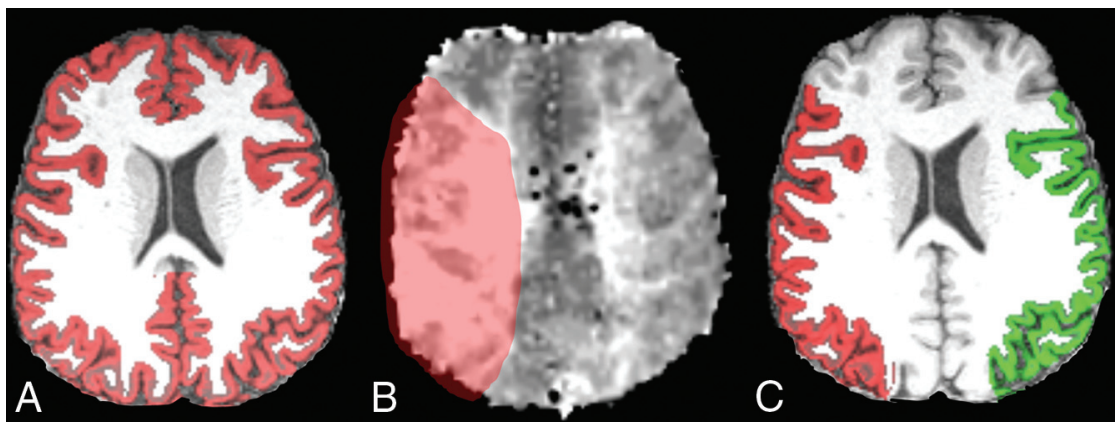

FIG 2. A, Skull-stripped T1-weighted image with an overlaid cortex mask. B, Enlarged TTP lesion mask (red) for definition of perfusion-delayed cortical areas. C, Perfusion-delayed cortical areas (red) and corresponding contralateral normoperfused cortex (green) overlaid on a T1-weighted image. Same patient as in Fig 1. different degrees of TTP delay was not deemed feasible. Therefore, only cortical areas were included that depended, with an extremely high likelihood (considering all available imaging data including CTA/ MRA and DSA to assess a potentially adjusted watershed area, the presence of communicating arteries, and so forth), on the stenosed/occluded artery and should have been affected by resulting perfusion abnormalities (Fig 2). Parameter values from WM areas with different ranges of TTP delay and from cortical areas were compared with values from corresponding contralateral unaffected areas by mirroring the ROIs to the contralateral side. To determine relative changes within hypoperfused tissue, we calculated a hemispheric asymmetry index (AI) for each parameter using the following equation ${ }^{23,24}$ :

$$
A I=\left(R_{\mathrm{i}}-R_{\mathrm{c}}\right) /\left(R_{\mathrm{i}}+R_{\mathrm{c}}\right) \times 2
$$

where $R_{\mathrm{i}}$ and $R_{\mathrm{c}}$ represent the ROI values in the ipsilateral and contralateral hemispheres, respectively. For a comparative morphometric measure, the volumes of affected WM and hypoperfused cortex (including visible lesions) were determined on the segmented T1-weighted images and compared with tissue volumes on the contralateral side. Before volumetric analysis, the tissue maps were linearly coregistered to standard space (Montreal Neurological Institute 152, 1 mm; http:// www.bic.mni.mcgill.ca/ServicesAtlases/) using $6 \mathrm{df}$ to minimize interpolation errors.
CPP. ${ }^{16,22}$ The binary WM and cortex masks were applied to the qT2 and PWI parameter maps to generate WM and cortex maps for each parameter (Fig 1, lower row). After the masking procedure, macroscopically visible lesions (including DWI lesions) were automatically removed from the respective parameter maps (On-line Figure). The second T2-weighted raw image ( $\mathrm{TE}=86$ $\mathrm{ms}$ ) from each patient was thoroughly inspected and manually corrected if necessary to exclude residual visible lesions or to avoid removing parenchyma beyond the edges of the lesions.

3D ROIs were defined on the basis of areas with TTP delay in the affected hemisphere. For WM, an elliptic periventricular ROI was placed in the unaffected hemisphere. The mean TTP plus 2 SDs was defined as the upper limit of normoperfusion and was used as a lower threshold for TTP maps. On the basis of this threshold, different degrees of TTP delay were determined by gradually increasing the threshold in intervals of 2 seconds (eg, 0-2 and 2-4 seconds, up to the maximum TTP delay) (Fig 1, upper row). For the cortical ribbon, the delineation of areas with

\section{Statistical Analysis}

Statistical analysis was performed using SPSS 22 (IBM, Armonk, New York). Because several parameters were not normally distributed (Kolmogorov-Smirnov test), we only used nonparametric statistical testing. Parameter values between corresponding ROIs (ipsilateral/contralateral hemispheres) were compared with the 2-sided Wilcoxon signed rank test. For evaluation of a parameter correlation, the 2 -sided Spearman signed rank test was used. A $P<.05$ was considered statistically significant. Correction for multiple statistical testing was done by performing false discovery rate correction for all parameters. Data are given as mean \pm SD unless indicated otherwise.

\section{RESULTS}

The mean age of the patients ( 15 men, 3 women) was $57.7 \pm 14.8$ years (range, $28-83$ years). Sites of stenosis and occlusion were the extracranial ICA $(n=8)$, the proximal MCA (M1 segment) $(n=7)$, and the intracranial ICA $(n=3)$. The right hemisphere was affected in 9 patients, while the other 9 patients had a left-sided pathology. 


\begin{tabular}{|c|c|c|c|}
\hline $\begin{array}{l}\text { Patient } \\
\text { No. }\end{array}$ & Age/Sex & $\begin{array}{c}\text { Site of } \\
\text { Stenosis/Occlusion }\end{array}$ & $\begin{array}{l}\text { Affected } \\
\text { Hemisphere }\end{array}$ \\
\hline 1 & $42 / M$ & Extracranial ICA & Right \\
\hline 2 & $28 / \mathrm{M}$ & MCA MI & Left \\
\hline 3 & $49 / \mathrm{M}$ & Extracranial ICA & Left \\
\hline 4 & $36 / M$ & MCA MI & Right \\
\hline 5 & $53 / \mathrm{M}$ & Intracranial ICA & Right \\
\hline 6 & $60 / M$ & Extracranial ICA & Left \\
\hline 7 & $82 / M$ & Extracranial ICA & Right \\
\hline 8 & $53 / \mathrm{M}$ & Extracranial ICA & Right \\
\hline 9 & $83 / F$ & MCA MI & Left \\
\hline 10 & $62 / M$ & Extracranial ICA & Right \\
\hline 11 & $53 / F$ & MCA Ml & Right \\
\hline 12 & $67 / M$ & Intracranial ICA & Left \\
\hline 13 & $64 / M$ & Extracranial ICA & Right \\
\hline 14 & $49 / \mathrm{M}$ & MCA M1 & Left \\
\hline 15 & $50 / \mathrm{M}$ & MCA M1 & Left \\
\hline 16 & $75 / F$ & Extracranial ICA & Right \\
\hline 17 & $70 / \mathrm{M}$ & MCA M1 & Left \\
\hline 18 & $62 / M$ & Intracranial ICA & Left \\
\hline
\end{tabular}

Seven patients were recently symptomatic (stroke or TIA within the last 30 days before MR imaging), 6 had been formerly symptomatic (several years before MR imaging examination), and 5 patients had a completely asymptomatic vascular pathology. Demographic and clinical baseline characteristics for all patients are summarized in the Table. Four patients showed small $\left(<10 \mathrm{~cm}^{3}\right)$ ischemic lesions on DWI, which were removed from the parameter maps before further analysis as described above.

\section{qT2 and Perfusion Parameters within Perfusion- Restricted Normal-Appearing WM}

In normal-appearing WM with any TTP delay ( $>0$ seconds, entire TTP lesion) ipsilateral to the vessel pathology, T2 values were significantly increased compared with corresponding contralateral normoperfused areas $(110.08 \pm 19.27 \mathrm{~ms}$ versus $106.39 \pm 15.71 \mathrm{~ms}$, $\mathrm{AI}=3.07 \% \pm 4.1 \%, P=.008)$. Perfusion parameters also showed significant changes within the entire TTP-delayed area with significant decreases of $\mathrm{rCBF}(\mathrm{AI}=-15.57 \% \pm 12.38 \%, P=.001)$ and an increase of $\mathrm{rCBV}(\mathrm{AI}=5.8 \% \pm 9.68 \%, P=.041)$, resulting in a significant decrease of the $\mathrm{rCBF} / \mathrm{rCBV}$ ratio $(\mathrm{AI}=-22.11 \% \pm$ $11.94 \%, P<.001)$ compared with contralateral unaffected areas. These changes were coherent for the respective parameters at different degrees of perfusion delay, except for a low TTP delay of 0-2 seconds and a severe TTP delay of 6-8 seconds (On-line Table). Asymmetry indices increased for qT2 and decreased for the $\mathrm{rCBF} /$ rCBV ratio with the increasing TTP delay (On-line Table). AI for qT2 showed a strong positive correlation with the TTP delay $(r=0.595$, $P<.001)$ and a strong negative correlation with the AI for $\mathrm{rCBF} /$ $\operatorname{rCBV}(r=-0.352, P=.002)$, with the latter showing a negative correlation with the TTP delay $(r=-0.570, P<.001)$ (Fig $3 A-C)$.

\section{qT2 and Perfusion Parameters within TTP-Delayed Cortical Areas}

Similarly, in the TTP-delayed cortex, qT2 was significantly elevated in comparison with the corresponding contralateral cortical areas of the unaffected hemisphere $(148.78 \pm 37.46 \mathrm{~ms}$ versus $142.58 \pm 31.18 \mathrm{~ms}, \mathrm{AI}=3.61 \% \pm 5.02 \%, P=.007)$. Analogous to the WM ROIs, significant decreases of $\mathrm{rCBF}(\mathrm{AI}=-7.35 \% \pm$
$12.88 \%, P=.022)$ and significant increases of $\mathrm{rCBV}(\mathrm{AI}=$ $11.24 \% \pm 45.53 \%, P=.013)$ were detected, resulting in significant decreases of the $\mathrm{rCBF} / \mathrm{rCBV}$ ratio $(\mathrm{AI}=-15.17 \% \pm 13.41 \%$, $P<.001$ ), compared with unaffected cortical areas (On-line Table). In contrast to WM, relative changes of $\mathrm{T} 2$ values in hypoperfused cortical areas did not correlate significantly with changes of perfusion parameters (AI qT2 versus TTP delay: $r=0.311, P=$ .21; AI qT2 versus AI rCBF/rCBV: $r=-0.292, P=.256$ ), while again a strong significant negative signed correlation was found between the $\mathrm{rCBF} / \mathrm{rCBV}$ AI and TTP delay $(r=-0.806, P<.001)$ (Fig 3D).

\section{Volumetric Analysis}

Volumes of affected WM and hypoperfused cortex did not differ significantly from volumes of the contralateral unaffected tissue $\left(269.33 \pm 25.5 \mathrm{~cm}^{3}\right.$ versus $270.81 \pm 27.29 \mathrm{~cm}^{3}, P=.372$ and $79.54 \pm 20.5 \mathrm{~cm}^{3}$ versus $\left.79.12 \pm 20.16 \mathrm{~cm}^{3}, P=.948\right)$. False discovery rate correction was performed for the respective parameters, and the corrected level of significance was $P=.033$.

\section{DISCUSSION}

This study revealed significantly increased qT2 values in perfusion-delayed normal-appearing WM and in cortical areas in patients with unilateral high-grade carotid occlusive disease compared with corresponding contralateral areas. In addition, these changes correlated with increasing hemodynamic failure as indicated by TTP delay, suggesting silent hypoperfusion-related microstructural tissue damage. Furthermore, the $\mathrm{rCBF} / \mathrm{rCBV}$ ratio seems to be a promising parameter to assess CPP in chronic cerebral hypoperfusion.

In patients with high-grade carotid stenosis-even asymptomatic_ qT2 showed a significant increase within normal-appearing GM and WM. This is in line with the literature findings, in which experimental studies revealed structural damage, including demyelination and axonal loss, in chronically hypoperfused brain parenchyma-in fact, the extent of structural damage correlated with the degree of perfusion impairment. ${ }^{8}$ In addition, glial activation has been demonstrated in experimentally induced chronic cerebral hypoperfusion. ${ }^{8}$ Gliosis in chronically hypoperfused tissue, which can be expected to cause prolongation of qT2 due to increased water content, may be caused by subtotal ischemic necrosis not leading to focal softening or cavitation (so-called "selective neuronal loss"). ${ }^{25,26}$ Hence, selective neuronal death may be one of the underlying causes of the significant prolongation of qT2 in normal-appearing hypoperfused tissue in this study. Furthermore, the qT2 increase in normal-appearing depending WM correlated significantly with the perfusion abnormalities depicted as perfusion delay on TTP maps, suggesting that the extent of tissue damage is related to the degree of perfusion delay. Most interesting, qT2 prolongation within hypoperfused tissue also showed a strong negative correlation with changes of the $\mathrm{rCBF} /$ rCBV ratio, which, for its part, correlated significantly with TTP delay (Fig $3 A-C$ ). By means of PET imaging, the $\mathrm{CBF} / \mathrm{CBV}$ ratio has been validated as an index of local CPP, ${ }^{16}$ which itself is a function of mean arterial blood pressure. Because obtaining rCBF and $\mathrm{rCBV}$ via DSC MR imaging (a bolus-tracking technique) is subject to various sources of imprecision and is technically fun- 

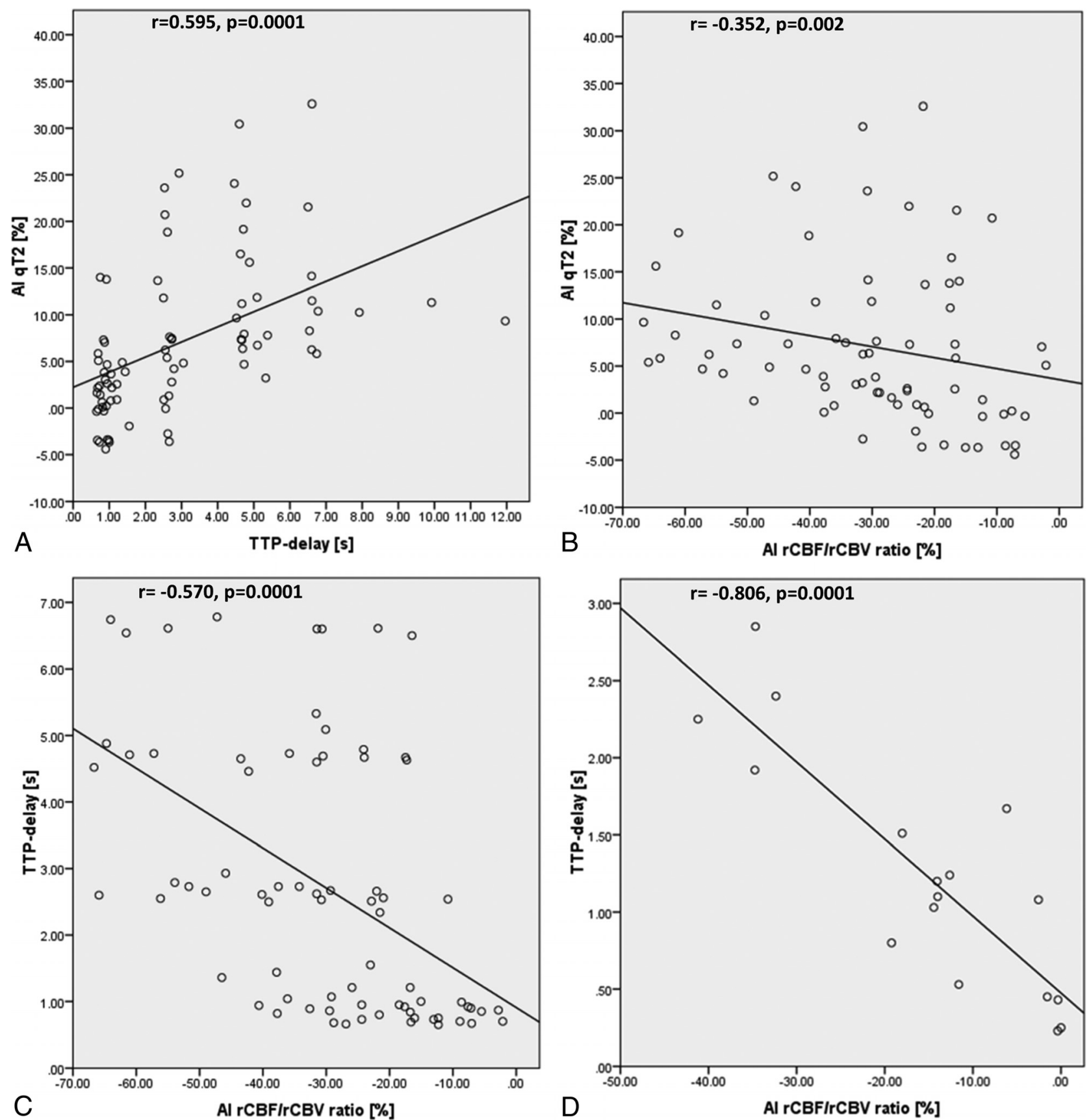

B

Al rCBF/rCBV ratio [\%]

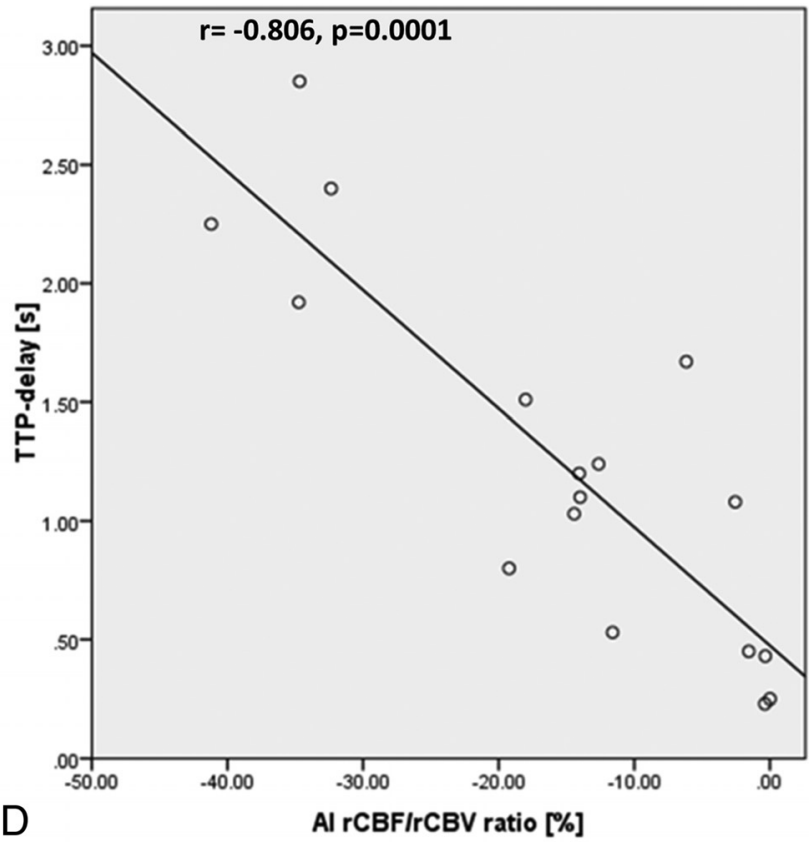

FIG 3. A-C, Scatterplots for seventy-four 3D WM ROIs, which were generated according to different degrees of TTP delay in all 18 patients. The number of data points per patient depends on the maximal extent of TTP delay in WM. A, The relationship between qT2 and TTP delay. $B$, The relationship between $\mathrm{qT} 2$ and the $\mathrm{rCBF} / \mathrm{rCBV}$ ratio. $C$, The relationship between TTP delay and the $\mathrm{rCBF} / \mathrm{rCBV}$ ratio. $D$, The relationship between TTP delay and the $\mathrm{rCBF} / \mathrm{rCBV}$ ratio in hypoperfused cortex for all 18 patients (1 data point per patient). For qT2 values and perfusion parameters (except time-to-peak for which the mean TTP delay is given), the graphs display the mean hemispheric asymmetry indices. Lines were obtained from linear regression analysis.

damentally different from measuring perfusion with PET, MR imaging-derived $\mathrm{rCBF} / \mathrm{rCBV}$ might not necessarily have the same significance. However, because TTP has been shown to correlate with $\mathrm{PET}$-derived $\mathrm{CBF} / \mathrm{CBV},{ }^{17}$ the finding of a significant relationship between the $\mathrm{rCBF} / \mathrm{rCBV}$ ratio and TTP delay in this study supports the hypothesis that $\mathrm{rCBF} / \mathrm{rCBV}$ obtained with DSC MR imaging could also reflect the local CPP. The significant correlation between qT2 and TTP as well as the $\mathrm{rCBF} / \mathrm{rCBV}$ ratio suggests that pathologic alterations of hypoperfused WM are mainly related to the degree of local CPP compromise, which determines the restriction of microvascular perfusion and oxygen supply and promotes microstructural tissue damage, even in normal-appearing tissue.

In cortical areas, the same changes of qT2 and perfusion parameters as in WM were detected, again indicating reduced perfusion pressure (On-line Table). Whereas a strong negative correlation between TTP delay and $\mathrm{rCBF} / \mathrm{rCBV}$ was also found in the hypoperfused cortex, no significant correlation of qT2 increase with perfusion measures was detected. This difference between the cortex and WM might be explained by the anatomic struc- 
ture of the respective supplying arterial vasculature. Because the perforating arteries supplying the deep WM are hardly collateralized, the extent of ischemic tissue damage depends on the severity of hemodynamic compromise. ${ }^{27,28}$ In contrast, a variable degree of leptomeningeal collateralization compensating for decreased perfusion can be expected in chronically hypoperfused cortex. ${ }^{29}$ This might explain why the magnitudes of both TTP delay and $\mathrm{rCBF} / \mathrm{rCBV}$ reduction within affected cortical areas are lower than in WM (On-line Table and Fig 3). On the other hand, the occurrence of embolism or microembolism, which is not necessarily directly related to perfusion abnormalities, might be more predominant as a mechanism of tissue damage in the cortex. ${ }^{30}$

That volumetric quantification of normal-appearing WM and cortex did not reveal significant volume reduction of hypoperfused tissue excludes relevant partial volume effects from CSF, with a resulting increase of tissue water as the reason for the increase of T2 values observed in this study. The different underlying causes of microstructural changes in hypoperfused tissue, which may include a variety of pathologies, cannot be differentiated with qT2 mapping. Because microstructural changes in carotid occlusive disease have been shown to regress partly after stent placement ${ }^{6}$ or carotid endarterectomy, ${ }^{11,31}$ the underlying mechanisms might also comprise (partially) reversible conditions, though the pathophysiologic correlate for this finding remains currently unclear.

In summary, the results of this study suggest the presence of microstructural alterations that are not assessable using conventional MR imaging within chronically hypoperfused tissue in patients with carotid occlusive disease and exhausted autoregulation. In addition, our results might support the hypothesis that the DSC-derived $\mathrm{rCBF} / \mathrm{rCBV}$ ratio could be used as an index of local CPP, comparable with TTP delay, as an appropriate indicator of hemodynamic failure in chronic cerebrovascular disease.

\section{Limitations}

This study has several limitations. First, perfusion values determined with DSC techniques only provide representative relative values, which must be compared with values from reference regions. Second, because this is not a longitudinal study, the temporal evolution of qT2 values and perfusion parameters and their possible response to reperfusion procedures was not evaluated. Third, although prolongation of qT2 has been described in chronic cerebral hypoperfusion and would be consistent with microstructural damage manifesting itself as gliosis and neuronal loss, a formal histologic validation of qT2 as a marker of microstructural tissue damage due to hypoperfusion is lacking. This should be pursued and further investigated in future studies. Additionally, the relationship between pathologic qT2 increases and clinical correlates such as cognitive performance must be investigated for the relevance in clinical practice. Finally, an investigation of qT2 changes in larger patient collectives with well-defined risk profiles and different statuses of reperfusion as well as a PETbased validation of MR imaging-based $\mathrm{rCBF} / \mathrm{rCBV}$ as an index of CPP would be of interest.

\section{CONCLUSIONS}

Quantitative T2 mapping seems to detect microstructural damage in chronically hypoperfused but normal-appearing cortex and $\mathrm{WM}$, which correlates with the degree of perfusion pressure impairment due to carotid occlusive disease. The $\mathrm{rCBF} / \mathrm{rCBV}$ ratio and the nondeconvolved TTP determined with DSC MR imaging seem to be suitable for detecting reduced CPP and hemodynamic failure in these patients. After further research to elucidate the clinical correlates of these parameters and their response to reperfusion, these techniques could help to identify patients at risk of progressive cognitive decline who would potentially benefit from revascularization.

Disclosures: Alexander Seiler-UNRELATED: Grants/Grants Pending: Goethe University Frankfurt, Faculty of Medicine.* Ralf Deichmann—RELATED: Grant: support to the Brain Imaging Center Frankfurt, Comments: Bundesministerium für Bildung und Forschung (Germany) DLR 01GO0203, Deutsche Forschungsgemeinschaft (Germany) ZA 233/1-1*; UNRELATED: Consultancy: Wellcome Trust Centre for Neuroimaging at UCL, London, UK, Comments: consultant for MR imaging scanner procurement; Employment: University of Frankfurt; Grants/Grants Pending: Land of Hesse, Germany: LOEWE research grant "Neuronale Koordination Forschungsschwerpunkt Frankfurt," 2011-2013 Deutsche Forschungsgemeinschaft: "Imaging of damage and repair in MS patients — Impact of new lesions on network activity, Teilprojekt B5" 2012-2016, Comments: public funding*; Royalties: published book chapters: 1) R. Deichmann, "Principles of MRI and Functional MRI." In: fMRI Techniques and Protocols. M. Filippi, ed. Humana Press, Springer, Heidelberg, 2009; 2) R. Deichmann, U. Noeth, N. Weiskopf, "The Basics of Functional Magnetic Resonance Imaging." In: EEG-fMRI. C. Mulert, L. Lemieux, eds. Springer, Heidelberg, 2010 (so far, no royalties paid); Travel/Accommodations/Meeting Expenses Unrelated to Activities Listed, Comments: occasionally travel expenses for invited lectures given at nonprofit organizations. Ulrike Nöth—RELATED: Grant: support to Brain Imaging Center Frankfurt, Comments: Bundesministerium für Bildung und Forschung (Germany) DLR 01G00203, Deutsche Forschungsgemeinschaft (Germany) ZA 233/1-1.* Waltraud Pfeilschifter-UNRELATED: Consultancy: Sanofi-Aventis; Grants/Grants Pending: Stryker Neurovascular, Boehringer Ingelheim, Medtronic*; Payment for Lectures Including Service on Speakers Bureaus: Stryker Neurovascular, Boehringer Ingelheim. *Money paid to the institution.

\section{REFERENCES}

1. Yamauchi H, Fukuyama H, Nagahama Y, et al. Evidence of misery perfusion and risk for recurrent stroke in major cerebral arterial occlusive diseases from PET. J Neurol Neurosurg Psychiatry 1996;61: 18-25 CrossRef Medline

2. Yamauchi H, Fukuyama H, Nagahama Y, et al. Significance of increased oxygen extraction fraction in five-year prognosis of major cerebral arterial occlusive diseases. J Nucl Med 1999;40:1992-98 Medline

3. Derdeyn CP, Grubb RL Jr, Powers WJ. Cerebral hemodynamic impairment: methods of measurement and association with stroke risk. Neurology 1999;53:251-59 CrossRef Medline

4. Derdeyn CP, Videen TO, Yundt KD, et al. Variability of cerebral blood volume and oxygen extraction: stages of cerebral haemodynamic impairment revisited. Brain 2002;125:595-607 CrossRef Medline

5. Caplan LR, Hennerici M. Impaired clearance of emboli (washout) is an important link between hypoperfusion, embolism, and ischemic stroke. Arch Neurol 1998;55:1475-82 CrossRef Medline

6. Cheng HL, Lin CJ, Soong BW, et al. Impairments in cognitive function and brain connectivity in severe asymptomatic carotid stenosis. Stroke 2012;43:2567-73 CrossRef Medline

7. Bakker FC, Klijn CJ, Jennekens-Schinkel A, et al. Cognitive impairment in patients with carotid artery occlusion and ipsilateral transient ischemic attacks. J Neurol 2003;250:1340 - 47 CrossRef Medline

8. Shibata M, Ohtani R, Ihara M, et al. White matter lesions and glial activation in a novel mouse model of chronic cerebral hypoperfusion. Stroke 2004;35:2598-603 CrossRef Medline

9. Tatemichi TK, Desmond DW, Prohovnik I, et al. Dementia associated with bilateral carotid occlusions: neuropsychological and 
haemodynamic course after extracranial to intracranial bypass surgery. J Neurol Neurosurg Psychiatry 1995;58:633-36 CrossRef Medline

10. Shiraishi A, Hasegawa Y, Okada S, et al. Highly diffusion-sensitized tensor imaging of unilateral cerebral arterial occlusive disease. AJNR Am J Neuroradiol 2005;26:1498-504 Medline

11. Sato $\mathrm{Y}$, Ito K, Ogasawara $\mathrm{K}$, et al. Postoperative increase in cerebral white matter fractional anisotropy on diffusion tensor magnetic resonance imaging is associated with cognitive improvement after uncomplicated carotid endarterectomy: tract-based spatial statistics analysis. Neurosurgery 2013;73:592-98; discussion 598-99 CrossRef Medline

12. Meng X, Jun C, Wang Q, et al. High b-value diffusion tensor imaging of the remote white matter and white matter of obstructive unilateral cerebral arterial regions. Clin Radiol 2013;68:815-22 CrossRef Medline

13. Sahin N, Solak A, Genc B, et al. Dilatation of the Virchow-Robin spaces as an indicator of unilateral carotid artery stenosis: correlation with white matter lesions. Acta Radiol 2015;56:852-59 CrossRef Medline

14. Wagner M, Helfrich M, Volz S, et al. Quantitative T2, T2*, and T2' MR imaging in patients with ischemic leukoaraiosis might detect microstructural changes and cortical hypoxia. Neuroradiology 2015; 57:1023-30 CrossRef Medline

15. Inglese $\mathrm{M}, \mathrm{Ge} \mathrm{Y}$. Quantitative MRI: hidden age-related changes in brain tissue. Top Magn Reson Imaging 2004;15:355-63 CrossRef Medline

16. Schumann P, Touzani O, Young AR, et al. Evaluation of the ratio of cerebral blood flow to cerebral blood volume as an index of local cerebral perfusion pressure. Brain 1998;121(Pt 7):1369-79 CrossRef Medline

17. Kajimoto K, Moriwaki H, Yamada N, et al. Cerebral hemodynamic evaluation using perfusion-weighted magnetic resonance imaging: comparison with positron emission tomography values in chronic occlusive carotid disease. Stroke 2003;34:1662-66 CrossRef Medline

18. Seiler A, Jurcoane A, Magerkurth J, et al. T2' imaging within perfusion-restricted tissue in high-grade occlusive carotid disease. Stroke 2012;43:1831-36 CrossRef Medline

19. Ostergaard L, Weisskoff RM, Chesler DA, et al. High resolution measurement of cerebral blood flow using intravascular tracer bolus passages, Part I: mathematical approach and statistical analysis. Magn Reson Med 1996;36:715-25 CrossRef Medline
20. Zhang Y, Brady M, Smith S. Segmentation of brain MR images through a hidden Markov random field model and the expectationmaximization algorithm. IEEE Trans Med Imaging 2001;20:45-57 CrossRef Medline

21. Volz S, U, Jurcoane A, et al. Quantitative proton density mapping: correcting the receiver sensitivity bias via pseudo proton densities. Neuroimage 2012;63:540-52 CrossRef Medline

22. Sette G, Baron JC, Mazoyer B, et al. Local brain haemodynamics and oxygen metabolism in cerebrovascular disease: positron emission tomography. Brain 1989;112(Pt 4):931-51 CrossRef Medline

23. Powers WJ, Press GA, Grubb RL Jr, et al. The effect of hemodynamically significant carotid artery disease on the hemodynamic status of the cerebral circulation. Ann Intern Med 1987;106:27-34 CrossRef Medline

24. Kado H, Kimura H, Tsuchida T, et al. Abnormal magnetization transfer ratios in normal-appearing white matter on conventional MR images of patients with occlusive cerebrovascular disease. AJNR Am J Neuroradiol 2001;22:922-27 Medline

25. Lassen NA. Incomplete cerebral infarction-focal incomplete ischemic tissue necrosis not leading to emollision. Stroke 1982;13: 522-23 CrossRef Medline

26. Baron JC, Yamauchi H, Fujioka M, et al. Selective neuronal loss in ischemic stroke and cerebrovascular disease. J Cereb Blood Flow Metab 2014;34:2-18 CrossRef Medline

27. Bisschops RH, Klijn CJ, Kappelle LJ, et al. Association between impaired carbon dioxide reactivity and ischemic lesions in arterial border zone territories in patients with unilateral internal carotid artery occlusion. Arch Neurol 2003;60:229-33 CrossRef Medline

28. Derdeyn CP, Khosla A, Videen TO, et al. Severe hemodynamic impairment and border zone-region infarction. Radiology 2001;220: 195-201 CrossRef Medline

29. Derdeyn CP, Shaibani A, Moran CJ, et al. Lack of correlation between pattern of collateralization and misery perfusion in patients with carotid occlusion. Stroke 1999;30:1025-32 CrossRef Medline

30. Moriwaki $\mathrm{H}$, Matsumoto $\mathrm{M}$, Hashikawa $\mathrm{K}$, et al. Hemodynamic aspect of cerebral watershed infarction: assessment of perfusion reserve using iodine-123-iodoamphetamine SPECT. J Nucl Med 1997; 38:1556-62 Medline

31. Soinne L, Helenius J, Saimanen E, et al. Brain diffusion changes in carotid occlusive disease treated with endarterectomy. Neurology 2003;61:1061-65 CrossRef Medline 